\title{
PRÁTICAS DIDÁTICO-PEDAGÓGICAS DO DOCENTE NO ENSINO DE GRAMÁTICA $^{1}$
}

\author{
Gilberlânia Soares da Silva, Universidade Federal de Campina Grande (UFCG) \\ gilberlania89@hotmail.com \\ Joelma Maria de Abreu, Universidade Federal de Campina Grande (UFCG) \\ Joelmaberto2010@ hotmail.com \\ Maria Thaís de Oliveira Batista, Universidade Federal de Campina Grande (UFCG) \\ taholiveira.thais@gmail.com
}

\begin{abstract}
RESUMO
O ensino de gramática é sem dúvidas essencial para os falantes de uma língua, pois é através desta que passamos a entender o processo de formação das palavras e consequentemente desenvolvemos uma boa habilidade de leitura e escrita. Este artigo tem como objetivo relatar a importância da prática didático-pedagógica do docente para o ensino de gramática, assim como propor ideias para um aprimoramento de ensino nesta perspectiva. Partimos de uma pesquisa bibliográfica com o intuito de fazermos uma avaliação sobre o ensino de gramática por parte dos docentes. Enquanto aporte teórico tomamos por base as fundamentações e teorias de Antunes (2003), Travaglia (2009) entre outros. Os resultados apontam que o ensino de gramática deve ser repensado e adaptado para a atualidade e que a prática didático-pedagógica deve ser trabalhada intuitivamente para contribuir com a construção de uma nova forma de ensino.
\end{abstract}

PALAVRAS-CHAVE: Gramática; Ensino; Didática.

DIDÁTICO-PEDAGOGICAL PRACTICES OF THE TEACHER IN THE TEACHING OF GRAMMAR

\section{ABSTRACT}

The purpose of this article is to report the importance of the didactic-pedagogical practice of the teacher for grammar teaching. As a theoretical contribution, we have based the foundations and theories of Antunes (2003), Travaglia (2009) and others. The results point out that grammar teaching must be rethought and adapted to the present and that the didacticpedagogical practice must be intuitively worked to contribute to the construction of a new form of teaching.

KEY WORDS: Grammar; Teaching; Didactics;

\section{PRÁCTICAS DIDÁCTICO-PEDAGÓGICAS DEL DOCENTE EN LA ENSEÑANZA DE GRAMÁTICA}

\footnotetext{
${ }^{1} \mathrm{O}$ presente trabalho (não) contou com apoio financeiro de nenhuma natureza para sua realização.
} 


\section{RESUME}

Este artículo tiene como objetivo relatar la importancia de la práctica didáctica-pedagógica del docente para la enseñanza de gramática. Como aporte teórico tomamos por base las fundaciones y teorías de Antunes (2003), Travaglia (2009) entre otros. Los resultados apuntan que la enseñanza de gramática debe ser repensada y adaptada para la actualidad y que la práctica didáctico-pedagógica debe ser trabajada intuitivamente para contribuir con la construcción de una nueva forma de enseñanza.

PALABRAS CLAVE: Gramática; Enseñanza; Didáctica.

\section{INTRODUÇÃO}

Este artigo tem como objetivo relatar a importância da prática didático-pedagógica do docente para o ensino da gramática, assim como propor ideias para um aprimoramento de ensino nesta perspectiva.

O ensino de gramática é sem dúvidas essencial para os falantes de uma língua, pois é através desta que passamos a entender o processo de formação das palavras e consequentemente desenvolvemos uma boa habilidade de leitura e escrita, facilitando, assim, a comunicação. Mesmo este ensino sendo imprescindível na cultura de um povo, se faz necessário que possamos refletir sobre algumas indagações a fim de melhorias em relação à docência. Então, para que ensinar? O que ensinar? Como ensinar?

Para responder essas perguntas utilizamos uma pesquisa bibliográfica fundamentada nas teorias de Antunes (2003, 2007), Travaglia (2009) entre outros, que contribuiu para que chegássemos à conclusão que o ensino de gramática deve ser repensado e adaptado para a atualidade e que a prática didático-pedagógica deve ser trabalhada intuitivamente para contribuir com a construção de uma nova forma de ensino.

\section{COMPREENDENDO O ENSINO DE GRAMÁTICA A PARTIR DE UM OLHAR PANORÂMICO}

Neves (1990, p. 101) afirma que o ensino da gramática nas nossas escolas tem sido mais prescritivo, usando apenas as regras gramaticais, que todo ano são repetidas 
incansavelmente como sendo a melhor maneira e a mais correta de ensino. O que fica de lado são as atividades voltadas para a produção e compreensão de textos, sendo que na maior parte do tempo estão disponibilizadas a partir de tópicos gramaticais que são as classificações de palavras e sua flexão, análise sintática de período simples e composto, bem como noções de processos de formação de palavras e regras de regência e concordância, e também acentuação e pontuação.

Travaglia (2009, p.24) faz um parecer importante em relação à gramática, conceituando-a em três sentidos. No primeiro ele afirma que a gramática é um conjunto de regras para um bom uso da língua, e até mesmo para que esta possa ser expressa adequadamente. Desse modo, "a gramática é concebida como um manual com regras de bom uso da língua a serem seguidas por aqueles que querem se expressar adequadamente." (TRAVAGLIA, 2009, p. 24)

Um segundo conceito dado por Travaglia (2009, p.27) é que a gramática é descritiva, por fazer descrição estrutural e funcional da língua. Nesta concepção, a gramática tem como função retratar os fatos da língua, estabelecendo, assim, suas regras de uso.

A terceira concepção feita por Travaglia $(2009$, p.27) em relação à gramática é de uma gramática internacionalizada, ou seja, o saber que o indivíduo carrega consigo, um saber que não se aprende na escola, mas sim nas circunstâncias da vida e em suas vivências.

Nessa concepção de gramática não há o erro linguístico, mas a inadequação da variedade linguística utilizada em uma determinada situação de interação comunicativa, por não atendimento das normas sociais de uso da língua, ou a inadequação do uso de um determinado recurso linguístico para a consecução de um determinado recurso linguístico para a consecução de uma determinada intenção comunicativa, que seria melhor alcançada usando-se outro (s) recurso (s). (TRAVAGLIA, 2009, p.29)

Para responder as indagações feitas no início deste trabalho, tomamos as considerações feitas por Neves (1990, p.10-11), na qual faz um levantamento das respostas de professores sobre a seguinte pergunta: para que ensinar? Dos professores entrevistados, cerca de cinquenta por cento fazem menção ao bom desempenho, destacando o desempenho ativo, melhor expressão, melhor comunicação e melhor compreensão. Outros trinta por cento referem-se a questões normativas, visando conhecimento de regras ou de normas, conhecido como conhecimento de padrão culto; e temos ainda vinte por cento que atentam para a finalidade teórica (aquisição das estruturas da língua, melhor conhecimento da língua), 
conhecimento sistemático e apreensão de padrões da língua; ao ponto que quase um por cento dos professores falaram que dão aulas de gramática para cumprir programa, porém a finalidade está ligada ao melhor desempenho linguístico, registrado como falar e escrever melhor.

Neves $(1990$, p.12, 14) registra, também, que a maioria das indicações se relaciona ao melhor desempenho linguístico registrado e ainda diz que "falar e escrever, melhor", está ligado ao sucesso na vida prática. Tendo, assim, como objetivo principal o sucesso em concursos, bem como melhor desempenho social e profissional.

Em relação à pergunta: o que ensinar? Soares (1979, p.25) afirma "que não há consenso a respeito do ensino da gramática". Desse modo as escolas e professores trabalham ainda por meio de listas de tópicos gramaticais, que sistematicamente não ensinam gramática, mas apenas o uso da língua.

Em relação ao ensino da gramática, Neves (1990, p.18-28), faz um levantamento e diz que cinquenta por cento dos professores partem dos textos para exercitar a gramática; quarenta por cento diz partir de teorias e cinco por cento afirma que se atrelam as lições. Normalmente isso ocorre porque o livro didático infelizmente é a única fonte de consulta da grande maioria dos professores, mais especificamente no que diz respeito aos fatos da língua.

Soares (1979) nos apresenta três orientações metodológicas para o ensino de gramática: a primeira é chamada de gramática ao uso da língua, que vai ensinar as normas da língua e toda a teoria gramatical, pressupondo que o aluno conseguirá, a partir desse ensino normativo, usar a língua com eficiência. Será que esse tipo de ensino é eficaz? De acordo com vários autores não, pois o ensino da língua não está restrito ao certo e errado. Não podemos ter a gramática normativa como única verdade. A função do professor é oferecer condições ao aluno para que ele tenha competência para usar a língua nos mais diferentes contextos sociais. E apenas esse ensino normativo não é suficiente.

A segunda orientação dada por Soares (1979) é em relação ao uso da língua com a gramática. Esse tipo de ensino faz distinção entre "ensino da língua" e "ensino a respeito da língua”. Nessa orientação tem-se a valorização de que se aprende na prática, porém, não é o que realmente acontece, pois continua-se a prestigiar apenas a teoria gramatical, fazendo uma inversão que parte do exemplo para a teoria. E com essa inversão os conteúdos são aplicados aleatoriamente, perdendo-se a ideia de sistema, gradação de dificuldade e progressão da aprendizagem. 
Por fim, Soares (1979) considera a gramática como 'gramática do uso', pois busca o método e exercícios estruturais que por sua vez possibilita o desenvolvimento de novos recursos da língua. "Essa postura representa uma real inovação por valorizar realmente o uso, a produção lingüística, e não a descrição da língua (usando uma teoria linguística)" (SOARES, 1979, p.93).

Mesmo tendo uma postura de inovação, essa concepção tem suas falhas por apresentar as estruturas em função dos textos, sendo que ao invés disso, deveria preocupar-se com as dificuldades do aluno.

\section{POSSIBILIDADES DIDÁTICO-PEDAGÓGICAS PARA UM TRABALHO COM O ENSINO DE GRAMÁTICA}

Analisando a função da escola em relação à forma de ensinar aos discentes o estudo da gramática, a resposta seria como todos nós imaginamos que é ensinar a ler e escrever. Esse pensamento sobre tal função da escola perpassa de geração em geração, ao ponto que, enquanto estudantes o nosso papel desde as series inicias é ler e escrever, e dominar a língua de acordo com o ensino de gramática.

Saber gramática não é suficiente para atuarmos de maneira eficaz verbalmente. Essa concepção simplista reduz a condição para o uso da língua somente para competências gramaticais. Antunes $(203$, p. 55) chama atenção de que "Ninguém fala, ouve, lê, ou escreve sem gramática, é claro; mas a gramática sozinha é absolutamente insuficiente”, explica que para se compreender ou produzir um texto de cunho acadêmico, exige muito mais que um conhecimento de gramática.

Antunes (2003, p. 19) enfatiza que o estudo da Língua Portuguesa desde o Ensino Fundamental ainda acontece de maneira reducionista por meio de práticas pedagógicas que revelam estudos feitos de maneira descontextualizados através de palavras e frases. No entanto, é evidente que se precisam desenvolver reorientações de práticas, que venham a ser sistematizadas, planejadas e com participação das políticas públicas - federais, estaduais e municipais e professores em particular, para que as escolas tenham credibilidade ao preparar as pessoas para o meio social. 
O ensino da Língua Portuguesa não tem como único objetivo ensinar aos alunos um conjunto de regras que devem ser decoradas. $\mathrm{O}$ ensino da língua materna vai muito além dessa proposta tradicionalista.

O ensino da língua materna se justifica prioritariamente pelo objetivo de desenvolver a competência comunicativa dos usuários da língua (falante, escritor/ouvinte, leitor), isto é a capacidade do usuário de empregar adequadamente a língua nas diversas situações de comunicação. (TRAVAGLIA, 2009, p. 17)

Com base nesse pressuposto, devemos inserir os alunos nessa perspectiva que objetiva desenvolver sua comunicação e interação social, ao invés de apenas decorar regras gramaticais que, por muitas vezes, são jogadas sem contexto algum, e por esse motivo os alunos não conseguem aplicar em seu dia a dia, o que acaba transformando o ensino da gramática em algo cansativo e sem sentido.

A competência comunicativa, segundo Travaglia (2009, p. 17), por sua vez, implica o desenvolvimento de outras duas competências: a competência gramatical ou linguística que desenvolve a capacidade dos usuários da língua de gerar sequências linguísticas gramaticais aceitas na construção da língua. E desenvolve, também, a competência textual que é a capacidade de produzir e compreender textos.

Bem sabemos que a preocupação maior de alguns professores é ensinar a norma padrão aos alunos. $\mathrm{O}$ ensino da norma padrão tem sua importância e precisa ser alcançado, no entanto, a aplicação desse aprendizado é restrita a poucas formas de interação comunicativa. Já a competência comunicativa abrange muito mais possibilidades de uso em cada situação comunicativa do sujeito.

Diante disso, é necessário trabalhar a gramática de forma contextualizada, pois "a gramática está naturalmente incluída na interação verbal, uma vez que ela é uma condição indispensável para a produção e interpretação de textos coerentes, relevantes e adequados socialmente.” (ANTUNES, 2003, p.97). Uma ideia para o uso de gêneros textuais seria, por exemplo, usar a poesia, propaganda, música e etc., na intenção de gerar discussões entre os alunos, e a partir desses textos realizar estudo de gramática para que se possa compreender e identificar as informações contidas. A produção textual na escola, hoje, é de grande importância para o desenvolvimento do aluno, não apenas no âmbito escolar, mas também para a sua vida. 
Não se pode esquecer a importância da leitura, que é fundamental para o processo de formação, não só escolar, mas também de vida e de mundo. Ler não é apenas decodificar letras, mas sim saber interpretá-las, saber desvendar a mensagem que estar por além do código escrito.

A atividade de leitura favorece, num primeiro plano, a ampliação dos repertórios de informação do leitor. $\mathrm{Na}$ verdade, por ela, o leitor pode incorporar novas ideias, novos conceitos, novos dados, novas e diferentes informações acerca das coisas, das pessoas, dos acontecimentos, do mundo em geral. (ANTUNES, 2003, p.70)

A leitura desenvolve a capacidade de escrita do aluno e deve ser desenvolvida em sala de aula. Ler é uma prática de interação entre leitor/autor, em que o leitor deve buscar interpretar e dialogar com o texto, usando seus conhecimentos prévios. Antunes (2003) fala também da importância da leitura sem cobranças, ou seja, pelo simples gosto de ler.

Em relação aos gêneros textuais, por muito tempo a escola trabalhou sua identificação clássica: a narração, descrição e dissertação, ao ponto que estudos recentes mostram que esse tipo de abordagem tradicional prioriza apenas a forma. Bem sabemos que a concepção de gênero vai além da forma, pois, "Compreender um gênero implica considerar tanto o contexto quanto a situação em que um dado texto foi produzido" (ARAÚJO; ZAVAM, 2008, p. 13).

Marcuschi (2008, p.155) define gêneros textuais como "os textos materializados em situações comunicativas recorrentes" e que os gêneros fazem parte da na nossa vida diária. Já estudiosos da língua refletem e afirmam que o uso do gênero na sala de aula é a melhor forma de ensinar leitura, escrita, produção e gramática.

\section{CONSIDERAÇÕES FINAIS}

Pode-se perceber que o ensino de gramática na maioria das nossas escolas tem deixado muito a desejar, e esse fato acontece por muitos fatores, seja por falta de boas condições de trabalho, ou por falta de incentivo, ou mesmo ausência de professores qualificados, ou seja, a lista de dificuldades em relação ao ensino é muito ampla em nosso país. Vale ressaltar que o professor não é o único responsável pela educação, de modo que a sala de aula é o lugar de adquirir conhecimento, porém, muitas vezes o professor recebe a missão de educar alunos que deveriam vir educados de casa, mas a má condição familiar não contribui para essa parceria, o que acarreta outro problema. 
Para que se tenha um bom trabalho na educação é necessário que haja uma interação entre governo- escola- professor- aluno- família, de modo que todas as partes estejam envolvidas, para que se tenha, assim, crescimento e progresso.

Estas dificuldades envolvem não apenas o ensino de gramática propriamente dita, mas o ensino em geral. No que se refere à gramática, percebemos que estar sendo restritamente "ensinada" conforme o livro didático, que como sabemos é muito limitado e deve ser usado como material de apoio e não como único e exclusivo meio de ensino.

A gramática ensinada dessa forma, torna-se sem nexo, sem sentido e não é agradável aos olhos dos discentes. O ensino de gramática deve ser repensado e adaptado para a atualidade e a prática didático-pedagógica deve ser trabalhada intuitivamente para contribuir com a construção de uma nova forma de ensino. Poderíamos começar deixando de lado essa separação de conteúdo da língua portuguesa como: gramática, redação e literatura e passar a contextualizar de forma geral, através de gêneros e do próprio letramento, o que com certeza contribuirá para o ensino de nossa língua.

\section{REFERÊNCIAS BIBLIOGRÁFICAS}

ANTUNES, I. Aula de português: encontro \& interação. São Paulo: Parábola Editorial, 2003.

Muito além da gramática: por um ensino de línguas sem pedras no caminho. São Paulo: Parábola Editorial, 2007.

ARAÚJO, N.; ZAVAM, A. Gêneros escritos e ensino. In: PONTES, A. L.; COSTA, M. A. R. (orgs.). Ensino da língua materna na perspectiva do discurso: uma contribuição para o professor. Fortaleza: Edições Demócrito Rocha, 2008.

MARCUSCHI, L. A. Produção textual, análise de gêneros e compreensão. São Paulo: Parábola Editorial, 2008.

NEVES, M. H. M. Gramática na escola. São Paulo: Contexto, 1990.

SOARES, M. B. Novo português através de textos. São Paulo: Abril, 1982.

TRAVAGLIA, L. C. Gramática e interação: uma proposta para o ensino de gramática. 14 ed. São Paulo: Cortez, 2009. 
